\title{
New antithrombotic and antiplatelet treatment
}

\author{
K L Neuhaus
}

Thrombosis is the key pathological process in both unstable angina and acute myocardial infarction (MI). Treatment directed against the thrombus may consist of thrombolysis by plasminogen activators, thrombin inhibition, or platelet inhibition. Data from the TIMI IIIA and IIIB trials have shown conclusively that in contrast to their proven benefits in acute $\mathrm{MI}$, plasminogen activators make the prognosis worse in unstable angina. ${ }^{1-3}$ Thrombolytic treatment is therefore contraindicated in unstable angina, but new types of antithrombotic and antiplatelet agents now offer alternatives to heparin and aspirin.

\section{Thrombin inhibitors}

Specific thrombin inhibitors directly inhibit thrombin without the need for cofactors such as antithrombin III, and unlike heparin they inhibit both free and clot bound thrombin. In theory, this should result in superior efficacy, but clinical trials to date have failed to show that the theoretical advantages provide better results in practice. A major problem with all direct thrombin inhibitors is that they have a narrow therapeutic window, and at present they do not offer an alternative for unfractionated heparin (UFH) as the standard treatment for unstable angina.

The prototype direct thrombin inhibitor is hirudin, a naturally occurring polypeptide with a plasma half life of about one hour. The majority of clinical trials in this area have compared hirudin with UFH, but early trials in acute MI using hirudin (bolus of $0.4-0.6 \mathrm{mg}$ / $\mathrm{kg}$ and infusions of $0.15-0.2 \mathrm{mg} / \mathrm{kg} / \mathrm{h}$ for $48-96$ hours) in conjunction with thrombolytics found that the rate of intracranial haemorrhage was unacceptably high. ${ }^{4-6}$ In response to these results, the first trial in unstable angina, GUSTO-IIb, used much lower doses of hirudin (bolus of $0.1 \mathrm{mg} / \mathrm{kg}$ followed by infusion of $0.1 \mathrm{mg} / \mathrm{kg} / \mathrm{h}) .{ }^{7}$ However, the results were not very impressive with only a moderate reduction in the rate of death or MI at 30 days.

OASIS TRIALS

It is thought that the disappointing results of GUSTO-IIb may have been because the dosage reduction was too stringent, resulting in suboptimal treatment for those patients treated with hirudin. Higher doses (both the initial bolus and the infusion) were therefore used in the pilot OASIS trial. ${ }^{8}$ In this trial, 909 patients with unstable angina were treated with either hirudin $(0.2-0.4 \mathrm{mg} / \mathrm{kg}$ bolus followed by $0.1-$ $0.15 \mathrm{mg} / \mathrm{kg} / \mathrm{h}$ infusion) or UFH (5000 IU bolus followed by $1000-1200 \mathrm{IU} / \mathrm{h}$ infusion). Using a combined end point of death, MI, or refractory angina, the event rate at seven days was reduced by about $50 \%$ in the group treated with hirudin. Benefits persisted for at least six months. These results are not only significant but also clinically relevant. There was no excess of major haemorrhage with hirudin, and no intracranial bleeds were recorded, although the rate of minor haemorrhage was higher with hirudin than with UFH.

These results were felt to warrant further investigation and a much larger trial, OASIS-2, was set up. This major trial of over 10000 patients has now been completed and the results were recently published. ${ }^{9}$ Cardiovascular death or new MI within seven days occurred in fewer hirudin treated patients than $\mathrm{UFH}$ treated patients $(3.6 \%$ v $4.2 \%$, $\mathrm{p}=0.077)$. The proportion of patients with cardiovascular death, new MI, or refractory angina at seven days was also lower with hirudin than with UFH $\quad(5.6 \%$ v $6.7 \%$, $\mathrm{p}=0.0125)$. Hirudin was associated with a

\section{Trial acronyms}

CAPTURE:C7e3 Fab AntiPlatelet Therapy in Unstable REfractory angina

ESSENCE: Efficacy and Safety of Subcutaneous Enoxaparin in Non-Q wave Coronary Events

FRIC: FRagmin In unstable Coronary artery disease

FRISC: FRagmin during InStability in Coronary artery disease

GUSTO: Global Use of Strategies To Open occluded arteries

HIT: Hirudin for the Improvement of Thrombolysis

OASIS: Organization to Assess Strategies for Ischaemic Syndromes

OPUS: Orbofiban in Patients with Unstable coronary Syndromes

ORBIT: Oral glycoprotein IIb/IIIa Receptor Blockade to Inhibit Thrombosis

PARAGON: Platelet IIb/IIIa Antagonists for Reduction of Acute coronary syndrome events in a Global Organization Network

SYMPHONY: Sibrafiban Versus Aspirin to Yield Maximum Protection from Ischaemic Heart Events Post Acute Coronary Syndromes

TIMI: Thrombolysis In Myocardial Infarction

TRIM: ThRombin Inhibition in Myocardial ischaemia
Correspondence to: Dr Neuhaus
Klinik II, Städt

Kliniken, 41-43, 34125 Kassel, Germany

K L Neuhaus 


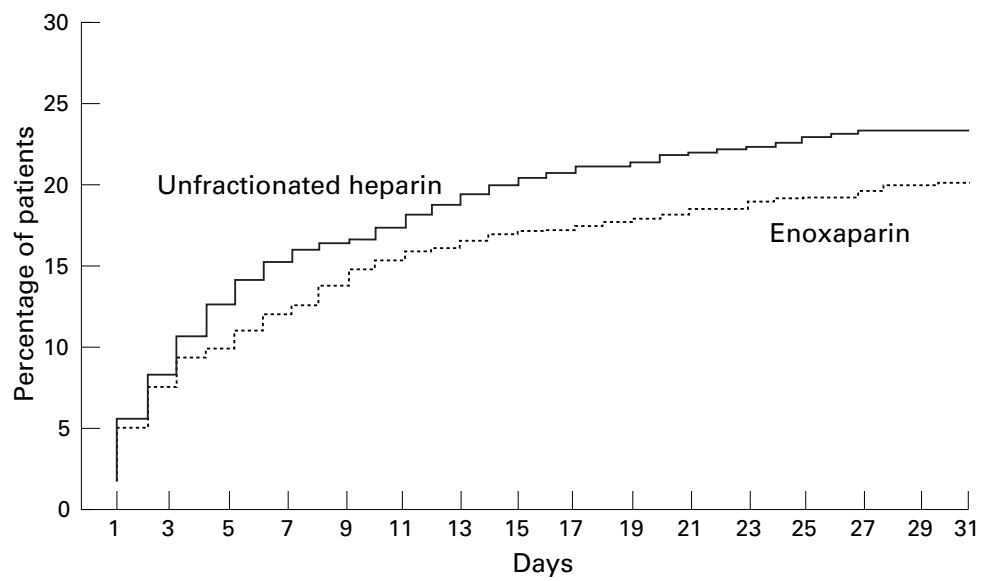

Figure 1 Kaplan-Meier plot of time to first event over a period of 30 days (composite end point of death, MI, or recurrent angina) in the ESSENCE trial. Reproduced from Cohen et al ${ }^{15}$ with permission of the Massachusetts Medical Society.

higher rate of minor and major bleeding episodes $(1.2 \% v 0.7 \%, \mathrm{p}=0.01)$. This difference was observed entirely in the first 72 hours with no excess in the subsequent period. The number of patients with life threatening bleeds was the same in both groups. The OASIS-2 investigators concluded that recombinant hirudin is superior to UFH in preventing cardiovascular death, MI, and refractory angina, with an acceptable safety profile in patients with unstable angina or acute MI without ST elevation.

OTHER DIRECT THROMBIN INHIBITORS

In addition to hirudin, a number of synthetic thrombin inhibitors have been produced. In general, the synthetic products have been found to be less effective than hirudin.

One such agent, inogatran, was compared to UFH in patients with unstable angina. ${ }^{10} \mathrm{At}$ both seven and 30 days, outcomes were better in the group of patients who had received UFH (bolus of $5000 \mathrm{IU}$ followed by infusion of $1200 \mathrm{IU}$ for 72 hours), and there was no evidence that inogatran (bolus of $1.1-5.5 \mathrm{mg}$ /

\begin{tabular}{|c|c|c|c|c|c|c|}
\hline Trial & Agent & Number & $\begin{array}{c}\text { Placebo } \\
(\%)\end{array}$ & $\begin{array}{c}\text { GP Ilb/IIla } \\
(\%)\end{array}$ & $\begin{array}{c}\text { OR } \\
(95 \% \mathrm{C}\end{array}$ & \\
\hline \multicolumn{7}{|c|}{ Percutaneous coronary intervention trials } \\
\hline EPIC & Abciximab & 2099 & 10.2 & 7.0 & $\rightarrow$ & \\
\hline IMPACT-II & Eptifibatide & 4010 & 8.4 & 7.1 & $\rightarrow$ & \\
\hline EPILOG & Abciximab & 2792 & 9.1 & 4.0 & - & \\
\hline CAPTURE & Abciximab & 1265 & 9.0 & 4.8 & $\rightarrow$ & \\
\hline RESTORE & Tirofiban & 2139 & 6.3 & 5.1 & $\longrightarrow$ & \\
\hline EPISTENT & Abciximab & 2399 & 10.2 & 5.2 & - & \\
\hline \multicolumn{7}{|c|}{ Unstable angina/non- $Q$ wave $\mathrm{Ml}$ trials } \\
\hline PRISM & Tirofiban & 3231 & 7.0 & 5.7 & $\rightarrow$ & \\
\hline PRISM PLUS & Tirofiban & 1570 & 11.9 & 8.7 & $\rightarrow$ & \\
\hline PARAGON & Lamifiban & 2282 & 11.7 & 11.3 & $\longrightarrow$ & \\
\hline PURSUIT & Eptifibatide & 10948 & 15.7 & 14.2 & & \\
\hline \multirow[t]{4}{*}{ Overall } & & 32735 & 11.1 & 9.0 & $\rightarrow$ & \\
\hline & & & & \llcorner & 1 & $\perp$ \\
\hline & & & & 0 & 0.5 & 1.5 \\
\hline & & & & & $\begin{array}{l}\text { PIIb/IIla } \\
\text { better }\end{array}$ & $\begin{array}{c}\text { Placebo } \\
\text { better }\end{array}$ \\
\hline
\end{tabular}

Figure 2 Incidence of death and myocardial infarction in an overview of trials of GP IIb/III a receptor inhibitors in acute coronary syndromes. Reproduced from Topol et al ${ }^{16}$ with permission of the Lancet. $\mathrm{kg}$ followed by infusion of $2-10 \mathrm{mg} / \mathrm{kg} / \mathrm{h}$ for 72 hours) had any dose related effect.

\section{Low molecular weight heparins}

The principal action of the low molecular weight heparins (LMWHs) is thought to be inhibition of factor Xa early in the coagulation cascade, ultimately inhibiting the generation of thrombin. This indirect thrombin inhibition is dependent on the presence of antithrombin III. Rebound thrombin activation with an increase in the clinical event rate after the cessation of $\mathrm{UFH}$ treatment is a recognised problem. Cessation of treatment with LMWHs is less likely to induce rebound since the half life of $\mathrm{LMWH}$ is prolonged in comparison to $\mathrm{UFH} .{ }^{11}$ A further advantage of LMWHs is that they are much easier to use than UFH or direct thrombin inhibitors, since they can be given by subcutaneous injection once or twice daily and do not require routine laboratory monitoring.

TRIAL RESULTS

Published clinical trials have compared LMWHs with both placebo and UFH in patients with unstable angina and non-Q wave MI. In the FRISC trial, a combination of aspirin and the LMWH dalteparin was found to reduce significantly the incidence of a combined end point of death or MI compared to aspirin alone. ${ }^{12}$ Benefits were concentrated among patients who had more severe acute coronary syndromes, as indicated by raised serum troponin T. ${ }^{13}$ A comparison of dalteparin with UFH in the FRIC trial found no significant difference between the two treatment groups for any of the clinical end points. ${ }^{14}$ However, the ESSENCE trial, which compared the LMWH enoxaparin with UFH found that both the rate of a combined clinical end point (death, MI, or recurrent angina) and the revascularisation rate at 30 days were significantly reduced by enoxaparin. ${ }^{15}$ The 30 day event rate (triple end point) among patients treated with enoxaparin was $19.8 \%$ compared to $23.3 \%$ among patients treated with UFH $(\mathrm{p}=0.02)$, and revascularisation rates at 30 days were $27.0 \%$ and $32.2 \%$, respectively $(\mathrm{p}=0.001)$. The time to first event was also delayed in patients treated with enoxaparin, relative to those treated with UFH (fig 1).

\section{Antiplatelet treatment: glycoprotein IIb/IIIa inhibitors}

Glycoprotein (GP) IIb/IIIa receptor inhibitors represent a major improvement over aspirin as antiplatelet agents. They act at the final common pathway in platelet aggregation, and early clinical trial results are very promising. The first of these agents, abciximab, is an antibody but there are also several semisynthetic non-antibody compounds with GP IIb/IIIa inhibition properties. Early agents all required parenteral injection, but some oral compounds are now undergoing clinical trials.

An overview of published trials of GP $\mathrm{IIb} / \mathrm{III}$ receptor inhibitors is shown in fig $2 .{ }^{16}$ This figure includes different trials with different agents in different indications. Overall, the 
odds ratio from trials in over 30000 patients was 0.79 in favour of GP IIb/IIIa inhibitors. The figure shows a class specific effect that there is a benefit of GP IIb/IIIa inhibitors over placebo. Trials of parenterally administered abciximab show a much greater qualitative reduction in adverse events than trials of other parenterally administered agents such as lamifiban and tirofiban. ${ }^{17-20}$ These four trials have all been done in patients undergoing percutaneous coronary intervention and show a drug specific effect; there was a more pronounced reduction in the end point of death or non-fatal $\mathrm{MI}$ at 30 days than that seen with other agents in this setting.

\section{ROLE OF REVASCULARISATION}

Most trials of GP IIb/IIIa receptor inhibitors have been undertaken in patients undergoing percutaneous transluminal coronary angioplasty (PTCA). However, PTCA is itself followed by a cluster of events, and the main benefits of GP IIb/IIIa receptor inhibitor treatment have been seen after revascularisation. One interpretation of these findings is that GP $\mathrm{IIb} / \mathrm{III}$ a receptor inhibition only reduced the additional risks presented by undergoing a revascularisation procedure. A full assessment of the effects of GP IIb/IIIa receptor inhibitors in unstable angina therefore requires data from trials in which patients were treated conservatively. Currently, there are few data of this type available. The CAPTURE trial ${ }^{18}$ included a preintervention phase, but most of the improvement was seen after PTCA, and it is not possible to say whether the benefits were caused by abciximab or the revascularisation. PARAGON, one of the few trials to date to address this issue directly, compared two doses of the GP IIb/IIIa receptor inhibitor lamifiban with heparin. ${ }^{21}$ At 30 days, there was no difference between lamifiban (either dose) plus heparin or heparin alone, although at six months there was a significant benefit from low dose, but not high dose, lamifiban treatment. These findings require further investigation before any conclusions can be drawn, but it appears that overall, non-antibody GP IIb/IIIa receptor inhibitors may be less effective than abciximab. ${ }^{1}$

ORAL AGENTS

Prolonged GP IIb/IIIa receptor inhibition beyond the acute phase will require agents that can be given orally. Several such agents have been evaluated in phase II trials and some are now entering phase III. The pilot ORBIT trial evaluated two different dosages of xemilofiban compared to placebo. ${ }^{22}$ The trial was underpowered to detect a difference in efficacy, but there was a clear difference in the rate of minor haemorrhage, mainly epistaxis and other mucosal bleeds. While the major haemorrhage rate was not increased, the dose dependent increase in minor bleeding is likely to have an adverse effect on patient compliance, an important consideration in a drug intended for long term use.

Two major trials of oral GP IIb/IIIa receptor inhibitors, involving more than 9000 patients each, are currently underway (OPUS TIMI $16^{\star}$ and SYMPHONY). When the results become available, it is hoped that they will show whether the concept of prolonged GP $\mathrm{IIb} / \mathrm{III}$ a receptor inhibition is indeed of benefit for patients. ${ }^{1}$

\section{Conclusions}

Despite the central role of thrombosis in both unstable angina and acute MI, they are different conditions and require different management. Clinical trial programmes have shown that there are distinct variations between different agents in the same class, and experimental data relating to one agent cannot be used to draw any conclusions about another agent in the same class.

Direct thrombin inhibitors were expected to offer a new approach to antithrombin treatment in acute coronary syndromes, but finding the right combination of safety and efficacy has proved difficult. Hirudin appears to be the most promising of these agents but the data currently available still do not justify a recommendation for routine use. LWMHs offer a good alternative to UFH. Their use is supported by the results of clinical trials showing that they are at least as effective, and in some cases - for example, enoxaparin-more effective than UFH. LMWHs have a similar safety profile, but are much easier to use and reduce the overall medical cost of treatment.

GP IIb/IIIa receptor inhibitors have been extensively studied in conjunction with PTCA and are now established as a significant advance over aspirin for patients undergoing invasive procedures. However, more data are still required to establish whether they also offer significant benefits to unstable angina patients treated conservatively. The optimum duration of treatment with both GP IIb/IIIa receptor inhibitors and antithrombin agents is not clear, and trials to investigate whether prolonged treatment offers additional benefits are ongoing. If it is established that continuing treatment beyond the acute phase improves the outcome, then the availability of agents that can be self administered by the patient at home will be the key to longer regimens becoming part of routine clinical practice.

1 Braunwald E, Muller JE, McCabe CH, et al. Early effects of tissue-type plasminogen activator added to conventional therapy on the culprit coronary lesion in patients presenting with acute ischemic pain at rest: results of the TIMI IIIA trial. Circulation 1993:87;38-52

2 Braunwald $\mathrm{E}$ for the TIMI Investigators. Effects of tissue plasminogen activator and a comparison of early invasive and conservative strategies in unstable angina and non-Qwave myocardial infarction: results of the TIMI IIIB trial. Circulation 1994:89;1545-56.

3 Ambrose JA, Almeida OD, Sharma SK, et al. Adjunctive thrombolytic therapy during angioplasty for ischemic rest angina: results of the TAUSA trial. Circulation 1994:90:6977 .

4 Neuhaus KL, von Essen R, Tebbe U, et al. Safety observations from the pilot phase of the randomized r-Hirudin for improvement of thrombolysis (HIT III study). Circulation 1994;90:1638-42.

*Enrolment for the OPUS TIMI 16 trial was prematurely halted in November 1998 because of an increase in mortality in one of the treatment arms of orbofiban compared with placebo at 30 days. No significant benefit in the combined triple end point of death, MI, and urgent revascularisation was demonstrated for orbofiban over placebo. Full trial results have not yet been published (source: 48th annual scientific session of the
American College of Cardiology, New Orleans, USA, March 7-10, 1999: American College of Cardiology, New Ore 
5 GUSTO IIa Investigators. Randomized trial of intravenous heparin versus recombinant hirudin for acute coronary syndrom $1994 \cdot 90: 1631-37$.

6 Antman EM for the TIMI 9A Investigators. Hirudin in acute myocardial infarction: safety report from the thrombolysis and thrombin inhibition in myocardial infarction (TIMI) 9A trial. Circulation 1994;90:1624-30.

7 Global Use of Strategies To Open occluded arteries (GUSTO) IIb Investigators. A comparison of recombinan hirudin with heparin for the treatment of acute coronary syndromes. N Engl F Med 1996;29:775-82.

8 OASIS Investigators. Comparison of the effects of two doses of recombinant hirudin compared with heparin in patients with acute myocardial ischaemia without ST elevation. Circulation 1997;96:769-77.

9 OASIS-2 Investigators. Effects of recombinant hirudin (lepirudin) compared with heparin on death, myocardial infarction, refractory angina, and revascularisation procedures in patients with ST eln patients with acute myocardial ischaemia wroce

10 Thrombin Inhibition in Myocardial Ischaemia (TRIM) Study Group. A low molecular weight, selective thrombin inhibitor, inogatran, vs. heparin, in unstable coronary artery disease in 1209 patients. Eur Heart f 1997;14:141625.

11 Hirsh J, Warkentin TE, Raschke R, et al. Heparin and lowmolecular weight heparin: mechanisms of action, pharmacokinetics, dosing considerations, monitoring, efficacy and safety. Chest 1998;114:489S-510S

12 FRISC Study Group. Low-molecular-weight heparin during instability in coronary artery disease. Lancet 1996;347: $561-8$.

13 Lindahl B, Venge P, Wallentin L. Troponin-T identifies patients with unstable coronary artery disease who benefit from long term antithrombotic protection. $\mathcal{F} \mathrm{Am}$ Coll Cardiol 1997;29:43-8.
14 Klein W, Buchwald A, Hillis SE, et al. Comparison of low-molecular-weight heparin with unfractionated heparin acutely and with placebo for 6 weeks in the management of unstable coronary artery disease. Fragmin in unstable coronary artery disease study (FRIC). Circulation 1997;96:618.

15 Cohen M, Demers C, Gurfinkel EP, et al for the ESSENCE Investigators. A comparison of low-molecular-weight heparin with unfractionated heparin for unstable coronary artery disease. $N$ Engl f Med 1997;337:447-52.

16 Topol EJ, Byzova TV, Plow EF. Platelet GPIIb/IIIa blockers. Lancet 1999;353:227-31.

17 EPILOG Investigators. Platelet glycoprotein IIb/IIIa receptor blockade and low-dose heparin during percutaneous coronary revascularization. N Engl f Med 1997;336:168996

18 CAPTURE Investigators. Randomised placebo-controlled trial of abciximab before and during coronary intervention in refractory angina: the CAPTURE study. Lancet 1997; 349:1429-34.

19 PARAGON Investigators. International, randomized, controlled trial of lamifiban, heparin or both in unstable angina. Circulation 1998;97:2386-95.

20 PRISM Study Investigators. A comparison of aspirin plus tirofiban with aspirin plus heparin for unstable angina. $N$ Engl f Med 1998;338:1498-505.

21 Harrington RA, Moiterno DJ, van de Werf F, et al. Delaying and preventing ischemic events in patients with acute coronary syndromes using the platelet glycoprotein IIb/IIIa inhibitor lamifiban [abstract]. F Am Coll Cardiol 1997; 29(suppl A):409A

22 Kereiakes DJ, Ferguson JJ, Masud AZ, et al. Sustained platelet GP IIb/IIIa blockade with oral xemilofiban: final results of the ORBIT trial [abstract]. Circulation 1997; 96(suppl I):385. 